\title{
New spaces, ordinary practices: circulating and sharing within diverse economies of provisioning
}

DOI:

10.1016/j.geoforum.2017.11.022

\section{Document Version}

Accepted author manuscript

Link to publication record in Manchester Research Explorer

\section{Citation for published version (APA):}

Holmes, H. (2018). New spaces, ordinary practices: circulating and sharing within diverse economies of provisioning. Geoforum, 88. https://doi.org/10.1016/j.geoforum.2017.11.022

\section{Published in:}

Geoforum

\section{Citing this paper}

Please note that where the full-text provided on Manchester Research Explorer is the Author Accepted Manuscript or Proof version this may differ from the final Published version. If citing, it is advised that you check and use the publisher's definitive version.

\section{General rights}

Copyright and moral rights for the publications made accessible in the Research Explorer are retained by the authors and/or other copyright owners and it is a condition of accessing publications that users recognise and abide by the legal requirements associated with these rights.

\section{Takedown policy}

If you believe that this document breaches copyright please refer to the University of Manchester's Takedown Procedures [http://man.ac.uk/04Y6Bo] or contact uml.scholarlycommunications@manchester.ac.uk providing relevant details, so we can investigate your claim.

\section{OPEN ACCESS}




\section{New spaces, ordinary practices: circulating and sharing within diverse economies of provisioning}

This article draws upon two distinct UK case studies to explore how alternative modes of provisioning employ ordinary practices of sharing and circularity. Speaking to debates about alterity, diverse economies (Gibson-Graham, 2008) and emerging literature on the circular and shared economy, these two small and informal based models, one food based, the other clothing, are put forward as examples of the vast array of contemporary 'alternative' forms of consumption and provisioning taking place across the UK. The article illuminates how diverse economies are 'made material' through their materials and practices. In doing so I make three key arguments: firstly, and overall, that studying materiality is one way to illuminate these new and emerging spaces of provisioning, highlighting their practices, intimacies and ambiguities. Secondly, this material focus illustrates how the practices of provisioning - in particular, sharing and circulating - are not new, but are instead organised in original and novel ways; and this has wider implications for contemporary debates on circular and shared economy. Thirdly, that the materials of provisioning can be both beneficial and troublesome to provisioning organisations' practices of circulating and sharing and the extent to which they tackle issues of social exclusion, financial hardship and sustainable resource use.

Keywords: Diverse economies, ordinary provision, circular economy, shared economy, materialities

\section{Introduction}

This paper considers the emergence of contemporary provisioning models and their materialities and practices. It argues that focusing on the materialities of diverse provisioning economies is one way to make sense of them, and that doing so reveals the ordinary practices of circularity and sharing which take place in these new and novel spaces. Through this focus it joins debates around the geographies of alterity and austerity with those of circular (CE) and shared economy (SE). Inspiration is drawn from Gibson-Graham's (2008) notion of 'diverse economies', alongside more recent work which illuminates the potential of alternative economic spaces and their intersections with CE/SE (Hobson, 2016; Ince and Hall, 2017). However, a key element of this paper is its consideration of ordinary, everyday economic practices; and for this it returns to the work of Ray Pahl (1984) and Alison Clarke (2001), both of whom have highlighted the informal, often taken-forgranted elements of informal economies and their focus upon sharing, circulating and reciprocating. 
Gibson-Graham's 'diverse economies' is a useful mechanism with which to think through contemporary alternative responses to global economic and political uncertainty. Models such as food banks, community food gardens, pay-what-you-can cafes and tool libraries, to name but a few, have been positioned as potential resolutions to the widening inequality gap created by global recession. Although such models are as diverse as they are similar, as a collective they promote progressive values around wellbeing, social justice and sustainability (Morgan, 2015). In the UK the impact of neoliberal austerity has been acute. In 20143.9 million people were in persistent poverty and $32.5 \%$ of the UK population reported experiencing relative income poverty at least once between 2011 and 2014 (ONS, 2016). With a persistent housing crisis (Shelter, 2016), continued uncertainty regarding the fallout from Brexit, and the yet to be felt long-term effects of benefits changes, alternative provisioning strategies have been developed across UK cities and towns with the aim of helping communities in financial hardship. Yet alongside more well-known and structured networks, such as The Trussell Trust, Incredible Edible, and The Real Junk Food Café, operates a plethora of other smaller often informal endeavours. The alterity of such strategies is up for debate and, as I illustrate, the concept of alternative provisioning is in itself an umbrella for an assortment of often paradoxical activities. Yet, these diverse endeavours demonstrate the heterogeneity of contemporary economic activity and the emergence of new economic spaces through which various forms of 'economy' are practiced and made material.

The popularisation and subsequent confusion regarding the supposedly recent economic formations of the sharing economy (SE) and the circular economy (CE) similarly serves to highlight the heightened heterogeneity of economic activity (Belk, 2014; Richardson, 2015; Schor in Schor et al., 2015). Although neoliberalism has provoked a resurgence of academic interest in the moral economy, as scholars critique the structured inequalities of capitalist political economies (Wilson and Jackson 2016; Morgan, 2015; Morris, 2016; Sayer, 2015), there is a dearth of scholarly literature dealing with these new and often contradictory economic formations and their place within the 'new crisis of capitalism' (Sonnino and Griggs-Treverthan, 2013: 272); not to mention how they intersect with contemporary spaces of provisioning.

Studies by Hobson (2016) and Hall and Ince (2017) have made a crucial step along this path. The latter illuminate the everyday embeddedness of sharing as economic practice 'existing beyond or at the edge of the commodified sphere' (p.4). Their edited collection draws upon a variety of compelling case studies to convey not only the complexity and ambiguity of sharing, but also how 
mutuality, solidarity and resourcefulness are a crucial component of sharing practices in times of crisis. The former similarly notes the embeddedness of economic practice. Bridging the lacunae between CE and SE, Hobson (2016) advocates the potential for 'rich engagement' (p.99) with the 'generative spaces' (p.98) and social enterprises of everyday activism. Such a focus enables an unrestricted approach to the possible realms of CE and SE, not bound by scale or space.

It is here where this article interjects. As Hobson concludes, further conceptual and empirical exploration of such spaces is required. Drawing upon the notion of diverse economies and an appreciation of the everyday embeddedness of sharing and circularity as economic practice, this paper uses two case studies, one a domestic clothes swap, the other a membership based food provisioning group, to empirically flesh out what such 'generative spaces' look like, illuminating their varied scales and spaces. However, it also pushes further at these arguments. Firstly, it examines how these diverse economies are materially stabilized, or 'made material', through the practices of circulating and sharing, and inversely how materiality also 'troubles' them. In doing so, I illuminate how provisioning organisations challenge and also inadvertently reproduce inequalities and exclusion. This material focus draws upon the vast body of work on consumption, everyday practice and material culture (key examples texts include: Gronow and Warde, 2001; Miller, 1987, 2010; Gregson, 2007; Shove, 2003). Secondly, it returns to the work of Ray Pahl (1984) and Alison Clarke (2001) to illustrate how these practices are not new, but are rather age-old methods of selfprovisioning and getting-by, badged in original and organized forms. From swapping and sharing, making and mending, to exchange and barter, these ordinary practices and the materialities they encompass illuminate new economic spaces operating in between the gaps of 'alternative' and also 'emergency' provisioning.

The article begins with an overview of the complexity of the current economic landscape, and the contemporary positioning of provisioning. A review of the research this paper stems from and its methodological underpinnings follows. In the second part, attention turns to the two empirical case studies. I begin by detailing the structure and format of these new and novel diverse provisioning economies. I then illustrate how circularity and sharing practices are materially stabilised within these spaces of provision and their ordinariness revealed. Following this, I examine how the materialities of provisioning can not only stabilise the ordinary practices of circularity and sharing, but can also trouble them. 


\section{Situating provisioning}

\subsection{Diverse economies, morality and gifting}

Nearly 10 years ago Gibson-Graham (2008: 614) argued that 'projects of economic autonomy and experimentation' were 'proliferating worldwide'. These 'diverse economies' offered an opportunity for geographers to bring 'marginalised, hidden and alternative economies to light' (p.613). Building upon their prior concept of 'community economies' (2006), Gibson's-Graham's 'diverse economies' involves an expansive variety of global-local forms of alternative and non-market transactions, paid and unpaid forms of labour, and alternative capitalist and non-capitalist types of enterprises. Drawing on feminist economics, but also notions of the social economy, this broad brush approach captured the heterogeneity and experimental aura of the then economic climate. It also circumvented the ongoing fierce debates about what is 'alternative' within the economy. Through a focus on relationality and embeddedness, their work conceives alternatives as 'continuously made (and unmade) through economic performance', as opposed to thinking about them as somehow 'out-there', pre-given constructs of an 'other' (Jonas, 2010: 7).

More recent academic work has taken up Gibson-Graham's gauntlet of revealing diverse economies. Studies on community co-operatives (Coren and Clamp, 2014; Daya and Authar, 2012; Paddock, 2015), farmer's markets (Tchoukaleyska, 2013; Vecchio, 2011) urban growing projects (McClain et al., 2014; Potter and Westhall, 2013), cultural festivals (Gibson et al., 2009), community alliances (Wills, 2012) and credit unions (Jones, 2008) are just a few of the multitude of scholarly responses. And this response itself has not gone unnoticed within the academic community (Fickley, 2011; Lee et al., 2008). Indeed, a research focus on the hidden, alternative and experimental within the economy endures, as scholars 'continue to refine what constitutes a diverse economy and alternative economic space' (Fickley, 2011: 237). Caught up in this space are other economic formations all aiding the creation of the heterogeneity of this plural economy (Amin, 2009). Alongside the popular social economy (Amin, 2009), the foundational economy (Leaver and Williams, 2014; Morgan, 2015), care economy (Zelizer, 2013) and compassion economy (James, 2010) all form part of this discourse; similarly drawing upon ideas of social justice, co-operation and working for the common good. This paper is firmly positioned within this persistent questioning of the contemporary economic landscape; aiming to illuminate, however trivial, partial or informal they may be, other economic spaces, formations and practices. 
Inherent within alternative and diverse economies is the notion of morality. As Sayer (2015: 292) notes 'all economies are moral economies in some respects', as they must all justify themselves and their actions. This reading complements the notion that these new economic spaces are not simply alterities to capitalism, as the two cannot be easily detached (Daya and Authar, 2012), but rather they are 'counter to the mono-culture of capitalism' (Gibson-Graham, 2008: 623). There is not the space in this paper to adequately engage with the extensive and often complex debates regarding the moral economy (see: Polyani, 1957; Sayer 2000, 2003; Thompson, 1991). Rather it is only suffice to say, that the concept of the moral economy, as both an object of study and as a method of enquiry, is deployed typically (although by no means exclusively) by the alternative economies literature as a means of appreciating: the ethics of care; importance of human agency; reciprocal relations; and collective and community action inherent in some economic activities. Closely entwined with the moral economy, and equally as contested, is that of the gift economy, and likewise this is not something this paper will focus on. Volunteering, donations of time, money, materials are all forms of gifts which are regularly given to provisioning organisations - emergency or otherwise. As Caplan (2016) notes, the donation of food to a food bank or the volunteers' time are both gifts. Yet, despite the prominence of morality and gifting as inherent features of provisioning, and undoubtedly features which are also 'made material', it is the practices of sharing and circularity which are at the core of this article.

\subsection{Circular economy and sharing economy}

The sharing and circular economies are both new and increasingly popular concepts, which have gained significant traction within the overall economic landscape. However, they are only now really starting to emerge within academic literatures (Martin, 2016). Furthermore, unlike the moral and gift economy which have a firm and recognised grounding in alternative provisioning, the scholarly link between SE and CE and such diverse provisioning economies has yet to be sufficiently made. Nevertheless, those studies which have engaged with SE and CE respectively, likewise note that they have a similarly contentious status as that of the moral and gift economy.

With regards SE, recent work, such as that of Hall and Ince (2017); Richardson (2015) and Schor et al., (2016) notes the concepts paradoxical framing, all at once having 'the capacity to be both alternative to and continuation of business-as-usual' (Richardson, 2015: 121). The incorporation of the likes of AirBnB and Uber under the rubric of SE only serves to emphasise capitalist undertones, and confuse the antinomies of alterity versus capitalism, ownership versus sharing; and monetary versus non-monetary organisations. This has led many to conclude that such endeavours should 
instead be known as the 'on demand economy', the 'access economy' or the 'crowdsourcing economy' (Schor et al., 2015: 17). Further complexity emerges when one considers what actually constitutes sharing within the SE. Schor et al., (2016) place an emphasis on trading; using four case studies, including a time bank, a food swap, a makerspace and an open access education site, to illustrate micro-level exchanges. Belk (2014b), however, would refer to such trading as a form of bartering or 'pseudo-sharing' because of the reciprocal nature of such exchanges and the ultimate transfer of ownership of goods. Rather, Belk (2014a:1596) stresses the need to recognise the distinction between 'non-ownership-based sharing and that which involves the transfer of ownership' and reciprocal exchange, including gift giving.

However, where consensus is reached is that the internet is facilitating a new era of sharing (Belk, 2014a), with a focus on 'access' as opposed to 'ownership' of goods (Botsman and Rogers, 2011) through digital platforms (Schor et al., 2015). Likewise, it is worth noting how scholars are linking the sharing economy to sustainable forms of consumption (Heinrichs, 2013; Martin, 2016, Botsman and Rogers, 2011). Such work refers to how the sharing of resources can reduce environmental impacts, such as car sharing reducing an individual's carbon footprint. However, they also reference the impacts of sharing on wider issues of waste. Heinrich's (2013: 230), for example, mentions upcycling and finding new uses for items; and indeed websites such as Freecycle and Yerdle are often deemed part of SE (Walker in Schor, 2015). Likewise, Product Service Systems (PSS) is a term which is beginning to creep into social science literature, referring to a business model which can foster schemes that enable the renting, upgrading and redesigning of materials (Tukker, 2015; Hobson, 2016; Piscicelli et al., 2015).

To date, the majority of work on CE has focused on large-scale manufacturing and industrial processes, and their adoption of closed loop, cradle-to-cradle processes to maximise efficiency (Ghunmi et al., 2016; Lieder and Rashid, 2016). Circular economy is defined by WRAP (2017) as a model which keeps resources in use for as long as possible, avoiding make-use-dispose linear models. However, recent political interest in the concept has propelled a shift, not only in its popularity, but also its reach. The European's Commission now has a 'Circular Economy Package' designed to help 'European businesses and consumers to make the transition to a stronger and more circular economy where resources are used in a more sustainable way' (European Commission, 2015). Likewise, the Ellen MacArthur Foundation is solely focused on promoting economic circularity that is 'restorative and regenerative by design' including business, government and academia (Ellen MacArthur Foundation, 2016). This wide-ranging endorsement of CE, alongside its 
political broadening to include consumers, has led a few academics to begin to question the scope and potential spatiality of the concept. As Hobson (2016: 99) argues, close attention needs to be paid 'to spaces where disparate forms of CE may emerge and/or be fostered in forms and ways that current analyses of the CE omits'.

In a previous study with others (Author), I argue for recognition of the domestic as a site of CE; where practices that constitute domestic life, including food sharing, repurposing and recycling, already involve the circularity of materials. Similarly, Hobson (2016: 96) alludes to the importance of the household, and the materials which flow in and out, in expanding CE's realm. In addition, and as already noted, connections are being made between CE and SE. Lacy and Rutqvist (2015) describe the sharing platform, and the likes of Uber and Lyft Inc, as CE business models. Whilst not expressively stating the varying forms of economy at work, research by Niinimaki and Hassi (2011) likewise draws upon the links between PSS schemes involving fashion items, and more sustainable, circular modes of consumption. Thus, it is evident that the division between SE/CE is blurred and the two are often interwoven. Hobson (2016) also makes these connections to PSS and the interweaving of CE/SE, referencing models such as Zipcar. However, Hobson (2016) pushes at this further, referring to social enterprises and 'generative spaces' (p.98) of everyday activism, such as repair cafes, as spaces of the CE. Hobson's work bridges the lacunae between the sharing and circular economies, opening up the possibilities that diverse economic spaces offer to issues of circularity, sustainability and activism. As Hobson states (2016: 99), there is potential for 'rich engagement, through both further conceptual and empirical exploration'. This article empirically fleshes out what such spaces look like and how they engage in practices of circulating and sharing.

Yet this paper pushes further at Hobson's argument through its focus on these activities being forms of ordinary practice, organised and structured in original and novel ways. The notion of the diverse economy echoes the sentiments made in Ray Pahl's (1984) earlier seminal work 'Divisions of Labour' to reveal taken for granted, mundane, everyday economic activities. As Pahl (1984:251) concludes, such practices are 'not so much a coping mechanism of the poor, as a reflection of a particular kind of lifestyle based on the skills and reciprocities of the work of everyday life'. The work of Richard White (2009) offers an updated confirmation of Pahl's earlier conclusions, noting how 'mutual aid' in both deprived and affluent neighbourhoods plays a vital social role yet is still underestimated. Similarly, conclusions are made in the work of Hall and Ince (2017:9) and their recognition that sharing is not just a response to crisis (see also: Author, 2017; Smith and Stenning, 2006) but something which is 'embedded in everyday politics, ethics and relationalities'. As Belk (2014a: 1595) 
notes, the sharing economy is not the new economic exemplar that it is purported to be, but rather is a 'phenomenon as old as humankind'. Likewise, the work of Alison Clarke (2001) on the circulations of children's clothing through both informal networks and organised events, alongside that of Angela McRobbie (1989) on second hand clothing, not only highlights that notions of circularity, sharing and CE/SE have always been features of everyday, what we might term 'ordinary', economic practice, but also how the structures and spaces of such practices are changing.

This article illustrates how through a focus on materiality these new and emerging diverse economies, operating on the fringes of domestic and informal networks, can be illuminated: their practices, ambiguities and intimacies revealed. In many ways this material emphasis involves drawing upon a 'follow the thing' approach; trying to understand how the objects and materials of provisioning move into, through and out of these endeavours through circulating and sharing ('follow the thing' approaches track objects from raw material to disposal, examples include: Cook, 2004 on papaya; Norris, 2005 on discarded Western clothing). Yet, vitally it is also about appreciating what these materials of provisioning afford, the practices they enable and the value they hold to the organisation and its members/users. It involves addressing how their very materiality - their fibres, textures, patterns and forms (Miller, 2005) - influences what happens to them and how they are circulated and shared. It requires examining how they form part of people's biographies and in turn have biographies of their own (Humphries and Smith, 2014; Woodward, 2007). From challenging issues of social exclusion and sustainable resource use, to also inadvertently reproducing the very inequalities such endeavours seek to overcome, the materials of provisioning and the circulating and sharing they afford, bring to life such new and emerging spaces, and the very ordinary practices they encompass.

\section{Methods and data}

This paper emerges from a larger body of work researching everyday thrifty consumption through the lens of practice, materiality and temporality. This three year research project has involved working with households, and service users and providers to develop a critical understanding of the temporal landscape of thrifty consumption and the contours and gradients of both time spent engaging in thrifty practices, but also the temporal trajectories of various consumer goods. The research has been situated along a 30 mile transect in the North West of England, incorporating some of the least deprived and most deprived areas of the country (Indices of Deprivation, 2015). Using participant observation techniques, I have spent over 18 months volunteering in a number of 
third sector organisations, including a food bank, credit union, and a community growing scheme, to understand how they work, and appreciate the challenges they face. Alongside this, 30 participant interviews have been conducted with a diverse mix of people of varying socio-economic backgrounds, genders, ethnicities and ages along the transect. Interviewees have been recruited both through the organisations and also independently through snowballing techniques. Interviews have focused on the activities of making, mending, extending and lending and have incorporated creative methodologies including object interviews, cupboard audits and accompanied shopping trips.

The data for this paper has emerged from my collaborations with the third sector organisations and also the participants involved in my research. As with many research projects, working with one organisation has led me to be introduced to many others, and my work with the Coffee Club has emerged from my initial collaboration with the credit union. The clothes swap, alternatively, I was invited to by one of my participants, as it is something she runs twice a year. As per GibsonGraham's (2008) call to work experimentally with community economies my approach with these alternative spaces of provisioning, however informal they may be, has always been one of ethnographic co-production; giving voice to these alternative movements, supporting them and helping where I can. To this end, I have been involved in Coffee Club since its inception, having regular discussions with the club's organisers regarding logistics, membership and day-to-day running and the data for this paper comes from such conversations. Likewise, the data from the clothes swaps comes from both my interviews with the participant who organises them and taking part in one.

There are many alternative and diverse economic spaces this paper could discuss. Some, such as the Real Junk Food Project (see: therealjunkfoodproject.org/), the Incredible Edible network (see: http://incredibleediblenetwork.org.uk/), and Casserole Club (see: https://www.casseroleclub.com/) are already established workable models of provisioning, mapping the UK and beyond. Others, such as the two I have chosen to focus on, are small-scale, in the case of the clothes swap-domesticated, models - organised by one to two people and involving probably no more than 30 users/participants. Yet they are nonetheless significant alternative spaces of provisioning. Illuminating these hidden and marginalised models not only gives voice to those involved, but also promotes new and interesting forms of provisioning and consuming which can offer challenges to inequitable, unsustainable, capitalist economic modes. 


\section{The case studies}

\subsection{Case study 1: Coffee Club}

Coffee Club meets once a week in a local primary school in East Lancashire. The group started out as a coffee morning, ran by two (non-teaching) staff members at the school, Kate and Haiza, who were tasked with engaging parents, particularly parents from BME communities. As time went on Haiza and Kate got to know the parents, who were mainly women (and identifying as BME), and to understand some of the challenges they face on a weekly basis. One such challenge was providing decent food for their families on limited budgets. Between them, Haiza and Kate, devised a food element to Coffee Club, building upon Kate's previous experience and knowledge in establishing and running a local food bank. However, unlike a food bank model, which almost exclusively involves providing free food to service users, Kate and Haiza's model involves membership and payment. As Kate explains:

Coffee club provides access to incredibly inexpensive food...it's a non-means tested group. People access the group for one of three reasons: one that they want to alleviate food poverty, two that they want to have assistance with household budgeting, or three that they want to reduce food waste.

(Kate, interview, Coffee Club founder)

For $£ 4$ per month people can become a member. They then pay a further $£ 2.50$ per week. This entitles them to three bags of food per week, estimated at approximately $f 30-40$ retail value. Alternatively, people can pay-as-they-go, however, this costs $f 5$ per week. Therefore, becoming a member is cheaper at $£ 14$ per month, as opposed to $\mathrm{f20}$. Anyone can become a member, and Coffee Club has now opened its doors to members of the public and people who do not have children at the school. This has meant a number of the school's teachers joining and also the headmaster. The idea around charging people is to remove any shame or stigma attached to receiving food, as has been well documented by food bank literature (see: Caplan, 2016; Horst et al, 2014; Williams et al., 2016), and to provide some level of equitability amongst members. Members are contacted and reminded through an online Whatsapp group. 
The membership fee covers the cost of the food, which is derived from two sources. The first is free food which is provided by a local Tesco store under Fareshare's trial of the Foodcloud app (see: http://www.fareshare.org.uk/fareshare-foodcloud-in-tesco-stores/). This app works by alerting local organisations when surplus food becomes available. This is normally food which is about to reach its use-by/sell-by/best before date, and can no longer be sold at the store. It will generally have also gone through the stores reduction procedures, being reduced mid-morning to $90 \%$ of the cost, then $75 \%$, then $50 \%$, then $25 \%$ by early evening. At this point the organisations on the rota for that evening are contacted by text message through the app to alert them that food is available, how much there is and what it is - ambient (tins etc), fresh, chilled or frozen. Those organisations then reply to say they will or will not collect it that evening. The second source of food is from Fareshare and this is where the membership costs are used. The organisers pay $f 100$ per month for 25 trays of food. As per the Tesco food, this is food which is surplus, often close to its use-by/sell-by/best before date and is also a range of different food types, however, its branding shows that it is derived from a number of the big supermarket brands

The night before Coffee Club the Tesco food is collected by either Kate or Haiza and is stored in the school. On the morning of Coffee Club, a driver is paid (from the membership fees) to collect the Fareshare food from their depot approximately 20 miles away and deliver it to the school. The food is then laid out on tables - not dissimilar to a shop in terms of categorising different food types (see Figures $1 \& 2$ ), people pay their weekly fee, and the filling of bags (people must bring their own) begins. Haiza and Kate, and a couple of volunteers, stand behind the tables serving and are often assisted by Tesco staff sent from the local store to help out. Items are restricted to one or two of each thing, depending on availability. Any food leftover, after everyone has been served, is given to the school's breakfast club and after school club. Before the food arrives, and whilst people are being served, the members mingle having a coffee, swapping stories, advice and often recipes.
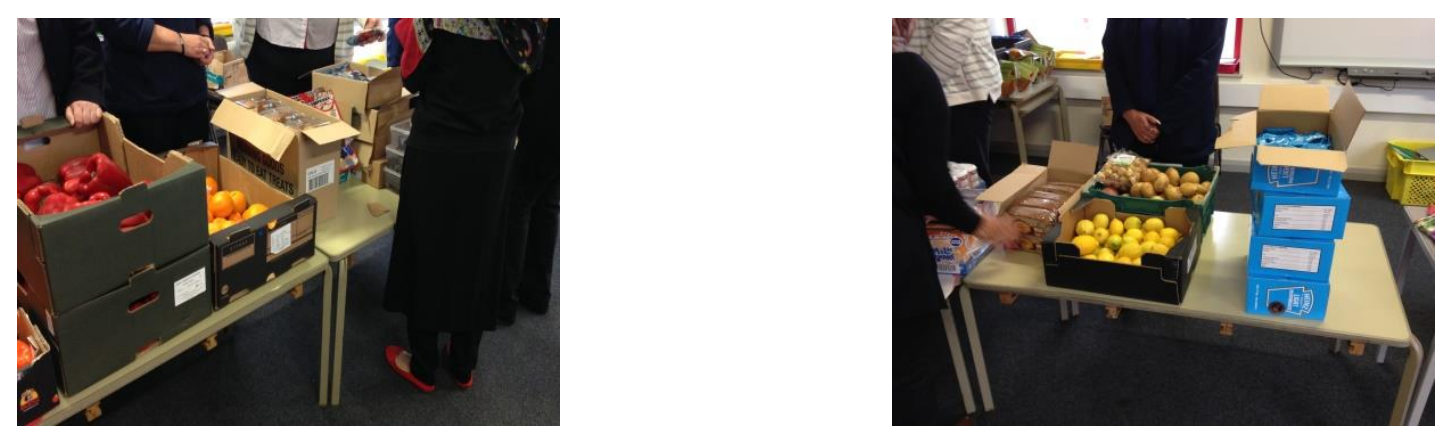
Figures 1 \& 2 - showing the food displayed ready for members at Coffee Club

As the above has indicated, the diverse economic space of Coffee Club is alive with practices of sharing and circularity, illuminated by the materials they provision. As Kate's initial quote illustrates, one of the group's main aims is to reduce food waste. This is captured and diverted from a variety of sources and re-circulated into the economy (alternative/diverse) to be consumed. This is could be likened to a CE model, whereby surplus food is redistributed rather than wasted and its energy and value released via its consumption, rather than its disposal. Not only is waste food being diverted from landfill/anaerobic digestion and used to its intended potential (e.g. being eaten), the locality of Coffee Club also ensures that such food is not travelling great distances to be dealt with, thus also negating any air pollution and energy use costs.

At a smaller scale we can also see other ways in which Coffee Club intersects with notions of circularity and sharing. Sharing (albeit 'pseudo-sharing' in Belk's (2014b) sense) occurs through the members' access to the food. Food is 'shared' by Tesco and other partners. Moreover, and in line with the concept of the new sharing economy as an internet based phenomena (Belk, 2014a; Schor in Schor, 2015), this is through the digital platform of Foodcloud. This then filters down through a further digital platform of the Whatsapp group between the members. The social element of coffee club also enables a number of other ways of sharing and circulating amongst members. One morning, one member bought in a stack of rhubarb she had grown which was going spare and shared it out to those who wanted it. As Pahl (1984: 250) notes the tasks of reciprocity and exchange performed for others are often an extension of tasks one already undertakes. In this case, the rhubarb was something the woman had grown for herself, but she was happy to share out the surplus as it was simply an extension of her own informal labour. Pahl's argument is further corroborated when we learn that the rhubarb was then returned, and re-circulated, some weeks later as jars of rhubarb and ginger jam that another member had made with the shared rhubarb. Furthermore, someone else then wanted to do a project which involved jam jars, so all the empty jars were then returned back into the group for this member to use. Thus, in this instance circularity and sharing intertwine and it is not entirely clear where one practice begins and another ends; rather they form part of these embedded ordinary practices of being part of the group.

However, it is not just material items which are circulated and shared through the diverse economic space of Coffee Club. Advice and skills are also a crucial element. As Kate has mentioned, the group 
teaches people to budget and 'making sure that people realise there is a cost involved, albeit small, so that they have to allow for it within their budget that week'. Yet such practices are wider than the original remit of the founders. As Kate notes 'people work on problems together'. One example concerns how to use different and unknown foods provided at group:

A lot of people have taken home foods they have never used before and have come back and reported that they managed to make soups or stews or incredible dishes, and such ideas and recipes get shared around.

(Kate, Coffee Club Founder)

In a similar vein to using new types of food, others have benefitted from new cooking skills:

We have got a member of staff who accesses it....he talks about how it's made a massive difference to him because he's learned to cook things. He didn't cook at all and now he cooks, so he's learned these skills through attending as well. (Kate, Coffee Club Founder)

Thus advice, knowledge and skills are also shared and circulated amongst the group. This is taken one step further if we consider the emotional support the group supplies:

It's quite a gentle group who are looking for ways to help each other. We had two families that have really needed [the] service, and we've received a written thank you from one of them actually.

From being space for people to discuss problems; to enabling others where English is not their first language to feel relaxed; to giving people the support they need during times of financial hardship, the group shares and circulates more than material goods but also forms of emotional and social support.

In the space of coffee club the material value of the provisioning objects, the food/tea and coffee, comes to be worth much more than its actual monetary value. As Kate notes 'because there's a sociable eating and drinking element, it makes people relaxed, and they want to chat'. Thus, the food acts as a conduit to provisioning much more than just itself, but also enables the circulating and sharing of less tangible and more emotional types of support. Thus Coffee Club's 'circular economy' 
is more than just materials. Yet, returning to the work of Pahl (1984: 137), none of these practices are new, 'the norms of reciprocity and complexity of social relationships surround the transaction'. These ordinary practices are embedded in the social relationships created by Coffee Club. What is extraordinary is the 'generative' (Hobson, 2015:98) spaces and structure which the group occupies; in this case a novel, non-emergency, membership-based provisioning group.

\subsection{Case Study 2: Clothes swap}

Clothes swapping is an increasingly popular phenomena; from dedicated 'swishing' websites (see: swishing.co.uk), to pop up clothes swapping events in vintage stores and community spaces (see: Purvis, 2014a); to more informal gatherings in people's homes, clothes swapping is seemingly replacing the jumble sale or bring and buys of the 1980s and 90s. In this case study I look at one such event, held bi-annually by one of my project's participants Rebecca. Rebecca is a full time mum of four in her 30 s. She lives in a three bed, semi-detached privately rented home in a quiet suburban area approximately ten miles outside of the city of Manchester. She started holding swapping parties several years ago due to a period of financial difficulty when her husband lost his job. Such parties have not just focused on clothes, but have included kitchen appliances, DVDs/CDs, children's toys and even recipes. As Rebecca explains, the impetus for holding them is 'to get a new wardrobe for the expense of a few things you no longer wear, whilst at the same time having a really nice time'. Rebecca is very focused on dignity and the swap providing dignity to those 'financially feeling in a bad position', or who may be struggling due to other personal circumstances, such as new mums trying to meet other people and deal with their changing bodies.

The parties generally involve approximately 15-20 attendees - all women; invited by Rebecca through Facebook. They are a mix of ages, sizes and backgrounds. Some know each other, but many only know Rebecca. Rebecca's 'mix' of people is deliberate, as she says herself she invites people she thinks might benefit from such an event, such as new mums:

I wanted to give it a community feeling.... with new mums it's important to get into a network that is friendly ... after being pregnant - you are forced into getting a new wardrobe as nothing is in the right place anymore... like last time I think we got ten new people which sort of mixes it up and it doesn't get cliquey'

Unlike some clothes swaps, there is no commitment to bring a set amount of clothes, nor are you only allowed to take away as many items as you bought (van der Zee, 2014); you can arrive with 
three items and leave with ten that is part of the ethos. Nor is it only clothing which is brought along, but shoes, accessories, and also jewellery; all of which is laid out and ordered around the downstairs of Rebecca's home. In the one I attended, Rebecca had clothing rails in her living room with dresses, jeans, trousers and tops all separated out (see Figure 3). Jackets and coats were on another rail in the hallway. In the playroom were accessories, with handbags arranged on top of a book shelf, and scarves folded neatly on the piano (see Figure 4); whilst in the kitchen, jewellery was arranged on her kitchen table (see: Figure 5), and shoes were sorted along a bench (see Figure 6), along with crisps and drinks available on the kitchen island. As I will go on to discuss, this element of display was important in the way that attendees engaged with the clothes and each other.

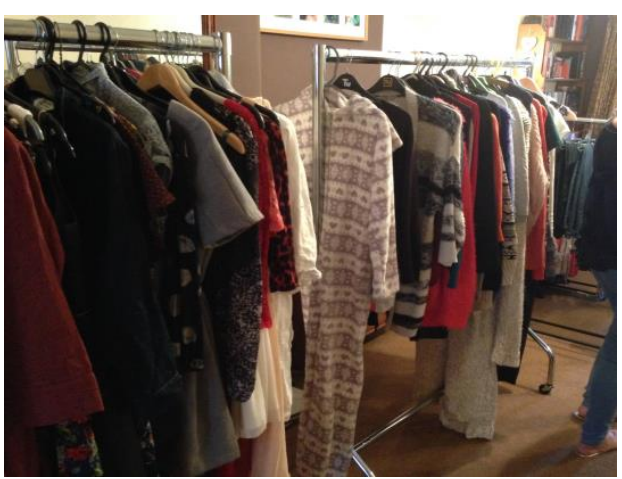

Figure 3 - rails of clothes

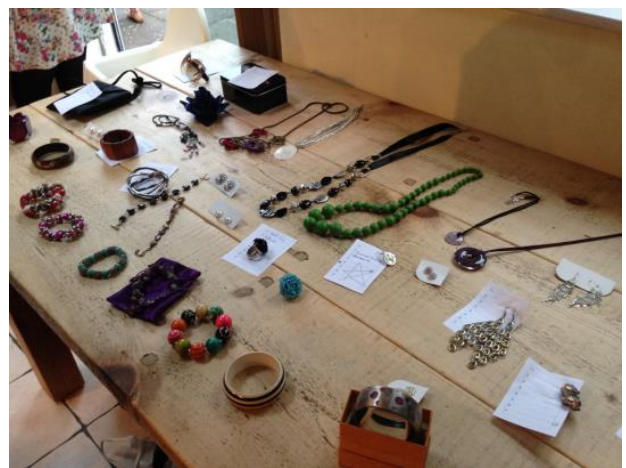

Figure 5 - jewellery on the kitchen table

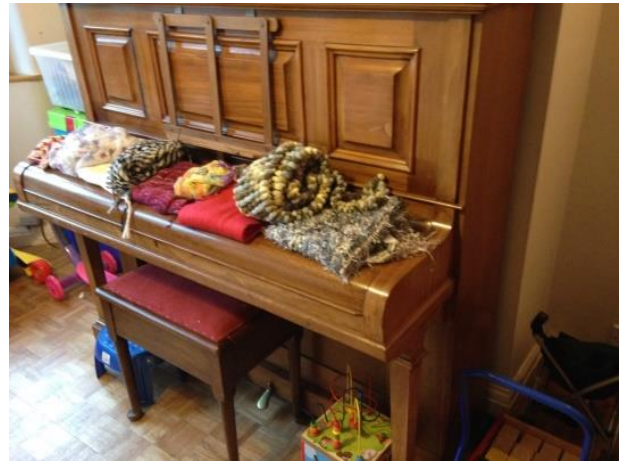

Figure 4 - scarves on the piano

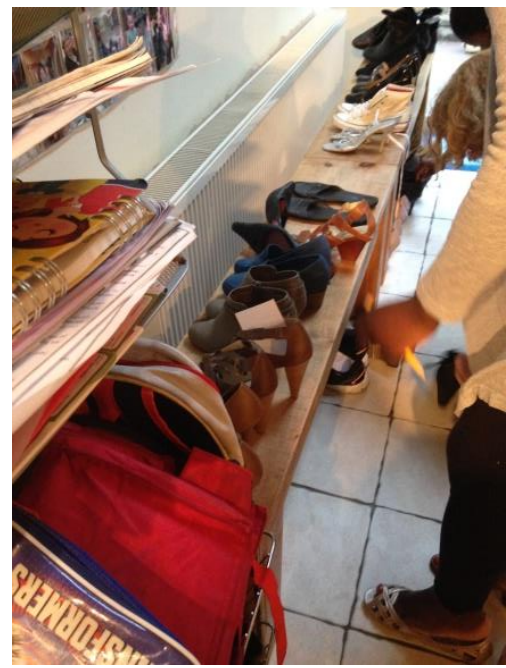

Figure 6 - shoes on the kitchen bench

As Rebecca explains the 'rules' of the clothes swap are as follows: 
'So you lay everything out, people come and browse for an hour and have these little tag things, and whatever you want, write on it what the item is and put your name in one of the boxes. If someone else comes along they write their name - and if no one else tags the item it's yours, but if other people have tagged it, it goes into a hat and you just pick one out. It feels fairer and it stops the kind of manic ness of running around and people trying to grab all the goods.'

During 'browsing' people were trying things on, getting changed in Rebecca's bathroom or holding items up in front of the full standing mirror she brought down from upstairs. Others would comment on what people were trying on, saying something looked nice, or have you tried it with these boots or this scarf. Often such comments might be from a complete stranger, but as Rebecca notes this is all part of the process of 'browsing, talking to other people. "Do you think that will suit?"'

As per Coffee Club, clothes swap offers a diverse economic space alive with the practices of sharing and circularity, materially stabilised by the very stuff of provisioning. According to WRAP (2011), 350, 000 tonnes of clothing is sent to landfill every year, whilst $30 \%$ of clothes in UK wardrobes have not been worn for at least a year. Whilst it could be contended that clothes swapping simply fulfils the same role as charity shops in re-circulating and re-purposing unwanted goods, there is an argument to be made that the practice of swapping encourages people to consider items in their wardrobes which are neither 'waste' nor 'want', but somewhere in a grey space of neither (see: Woodward, 2015 for a similar discussion regarding clothing; Gregson, 2007 and Hetherington, 2004 on general household objects; and also Evans, 2012 on food). Whilst anything can be sent to a charity shop and a great deal of it is sent for 'ragging' (Gregson, 2002; Norris, 2005), certain assumptions and judgements are made about what is suitable for swapping, and for others (soon to be known others) to see, touch, feel and potentially wear. Rebecca notes how people 'like to bring clothes or accessories that have been more special to them and are eager to see them go to a good home.' Often these items have a particular biography, such as a Ted Baker dress, brought along by one participant who recognised its kudos as a high end brand, but said it 'just was not her style', preferring something more 'biker' than 'floaty and feminine'. Others valued items because of particular sentiments they attached to them, such as remembering certain occasions when they had worn them, or perhaps people who had bought the items for them. For example, one woman bought along a pair of ornate clip-on earrings given to her by her mother-in-law. She loved the 
earrings but found them too uncomfortable to wear, hence why she wanted to bring them to the swap. Other biographies included items which no longer fitted, but because of their material qualities - made of valued materials such as wool and silk - participants wanted to ensure they got a second life. Thus, the value placed upon the clothing in terms of its life cycle, future possibilities and material state becomes critical to its circular status. Roger Lees (2010: 277) talks about economic geographies as 'material circuits of value, by means of which value is consumed, exchanged and produced through time and across space'. This is brought to life by Rebecca's practice of taking any leftover clothing to her local church for people to take, and anything still left over goes to the charity shop. Whilst this conveys the inherent domestic circular economy of the clothes swap, it also takes this one step further by illustrating that there are varying stages to the circular process, not unlike the now food waste pyramid (see: http://www.feeding5k.org/businesses+casestudies.php). Something similar can be seen with how Coffee Club passes on and recirculates surplus items to the school's breakfast club to avoid waste. In both instances, a process of circulation occurs through time and space, whereby items which have not been used as intended by the groups get 'passed on' to others who are deemed able to extract (or even add) value from them.

Again interwoven into this circularity are also notions of sharing. Rebecca talks about how stuff comes 'back around', with clothes re-appearing at subsequent clothes swaps, as people have had their wear out of them. Whilst this is part of the circular economy, it could also be classed as a form of sharing, as different people access the same clothes but at varying times. Rebecca also notes how often friends who cannot make the swap will still drop clothing off, essentially sharing it with the clothes swap, and might come and take a look at what is leftover at a later date. Once everyone has looked at the clothes for themselves, and items decided upon, Rebecca invites them to look for friends and family, essentially widening the circle. In a broader sense, circularity occurs through the removal of the usual parameters and expectations of shopping in store. There are no 'seasons' or 'trends' at clothes swap but rather an eclectic mixture, whereby thick winter jumpers can be found with summer dresses, and this season's latest trousers with thirty year old vintage dresses. Hence there is a distinct, almost stilted temporality, which does not mirror the normative consumptive trends of 'fast fashion' (Joy et al., 2012).

This 'slow' temporality created by the clothing becomes intertwined with the very ethos of clothes swap. Unlike shopping trips which can feel fraught and pressurised, clothes swap is literally a 'slow' form of consumption; people take their time, they browse, try on, chat, eat and drink. The 
materiality of the clothing, along with that of Rebecca's home, creates a very particular atmosphere. Attendees come together not just because of the materiality of the clothing, but because of the extra value this materiality affords; talking, laughing, advice, feeling part of a 'community' as Rebecca notes 'they can have a glass of wine and get to know each other and relax'. Thus, like Coffee Club the materiality of the clothing is a conduit to something greater than just the face value of the clothing. The clothing acts as a vehicle for the circulation and sharing of social and emotional forms of support. Whilst clothes swapping events are badged as a new phenomena, the swapping, sharing and circulating of clothing between social networks is not. As Alison Clarke's (2001) study on the circulations of children's clothing illustrates, this form of 'work' enables the creation of women's social spaces and the 'perpetuation of this sociality relies on the status of the material culture' (2000: 91). In other words, such events are as much about swapping clothes as they are about providing social networks. Like Coffee Club these are age old practices of provisioning, providing not just resource but also sociality (Belk, 2014b; Pahl 1984); what are different are the spaces and structures which they adopt. The new 'jumble sale', clothes swaps are organised through digital means, often taking place in domestic settings, and involve non-monetary exchanges, all the while focusing on sociality. They are an extraordinary form of economy, through the deployment of ordinary practices.

\section{Troublesome materialities}

Whilst the previous section examined how the ordinary practices of circulating and sharing are made material through new diverse economic spaces of provisioning, contrastingly this section examines how materialities can also unsettle them; essentially reinforcing the very inequalities such diverse spaces attempt to overcome. In both Coffee Club and clothes swap, the materials of provisioning can become troublesome, and rather than enabling the practices of circularity and sharing to take place their materialities instead unsettle them: causing issues and ruptures within the diverse spaces of provisioning. In their work on various sharing economy endeavours, Schor et al., (2015) discuss how inequalities are reproduced at a micro level. Using examples such as inappropriate food given in a food swap creating segregation, or hierarchies occurring between people and their skills at makerspaces, they illustrate how often 'the pervasiveness of inequality in the larger macro-economy is difficult to escape in new economic spaces' (p.78) (see also Wilson and Jackson's (2016) account of Fair Trade food). As I argue, such inequalities are similarly produced at the micro level within Coffee Club and clothes swap. However, I extend this argument to illustrate how such inequalities are very much grounded in the troublesome materialities and practices of provisioning. 
Within Coffee Club the troublesome materiality of food becomes apparent in several ways. Firstly, there are issues over providing food suitable for members' diets, as Kate explains:

It's quite challenging sometimes when... there's some people that are very very strict with their diet, as far as halal food is concerned.... So people often have this misconception that vegetarian equals halal, but it doesn't. We're learning as we go, really.

As Kate's quote illuminates, the practices of sharing and circulating food at Coffee Club are fraught with considerations; whereby food must be carefully micro-managed to ensure that people are receiving food suitable for their religious and cultural backgrounds. Secondly, and related to this, are issues around choice. As Kate notes, members are 'able to reject food that they don't want or can't use, or have enough of', but the choice of food available is still limited by what has been provided by the various sources. This is not a supermarket with heaving shelves of a plethora of goods. Likewise, there are issues over whether members should receive out-of-date and very close to date food, and if this is morally acceptable. This is often food which has been rejected by supermarkets maybe because it is slightly spoiling or the packaging damaged in some way. The idea of 'bad food for poor people', whilst the supermarket shopper receives 'perfect', fresh produce, does materially represent and reproduce inequalities at the micro level. Only those with adequate financial capital are able to access both unlimited choice but also food in its prime condition. More broadly, this links to critiques of charitable food models, regarding the depoliticising of food insecurity and the reproduction of neoliberal, pro-capitalist frameworks of 'Big Society' (Williams et al., 2016). From this stance, groups such as Coffee Club, and many other diverse provisioning organisations aimed at tackling social inequalities, are seen as filling the gap where the welfare state once was and should be.

Connected to matters of sustainability, Coffee Club's diversion of surplus/waste food from large scale supermarkets raises similar critique. There is no denying that taking Tesco's waste off them, alongside that of the many other major supermarket players whose waste ends up on the Coffee Club table, solves a rather problematic landfill or anaerobic digestion issue for such businesses; not to mention saving them huge sums of money with regards transportation of waste, landfill tax and/or anaerobic digestion fees (see: Gregson et al., 2015). Thus, models such as Coffee Club can be perceived as a free solution to the waste problems of the capitalist food industry. At a smaller scale, there are also waste challenges regarding what happens to anything left over which cannot be 
donated elsewhere. Despite Coffee Club's best diversion and circulation efforts, leftover, surplus food, still ends up in the same large scale waste structures as it would if discarded at source.

Within clothes swap troublesome materialities become apparent through issues of access. Firstly, most of the clothing available is only suitable for women size $8-16$, as Rebecca notes:

Yes coats, shoes and accessories - also helps with the size things, so if people are large and haven't got many clothes in their size at the swap, they can also look at the accessories - scarves, gloves, bags, hats.

Rebecca's recognises that clothes swap is in some way exclusionary, and does her best to solve this problem by ensuring that there is something there for everyone. However, this is clearly an issue of access. Linked to this, the majority of the clothing generally appeals to a younger age group, potentially excluding anyone older than say $35-40$. With both case studies there is a requirement to have access to the internet to be involved, and also the means to travel to the group to take part.

One of the biggest access issues and inequalities is the gendering of clothes swap -an all-female event, aimed at women and involving women's clothing. This is also an issue for Coffee Club which, whilst open to all, is still predominantly attended by women. Again this links to debates around neoliberal frameworks of 'Big Society', whereby volunteers, usually woman, replace public services and welfare provision (Caplan, 2015). Yet, whilst the connections to broader reproductions of neoliberal models cannot be denied - both Coffee Club and clothes swap are organised by women and attended predominantly by women - at the micro-level it could be argued that again this is about ordinary forms of provision. Neither clothes swap nor Coffee Club define themselves as offering emergency or charitable forms of provision. Rather, they deploy every day, informal practices of sharing and circulating structured and organised in novel ways. As previous research has illustrated, such ordinary practices of reciprocity, exchange, and mutuality have always been part of the gendered division of labour, and can be very much embedded in women's social networks (Clarke, 2001; Pahl, 1984, Smith and Stenning, 2006). Given that recent statistics report that in 2016 UK women are still doing $60 \%$ more unpaid work then men (ONS, 2016), then it is no surprise that these ordinary practices, the spaces in which they take place, and the materials of provisioning they involve are gendered. In other words, the gendering of these diverse economies serves to reinforce their ordinary aspects, and in doing so moves beyond neo-liberal critique of the provisioning sector and into wider and longer standing debates around gender inequality, the division of labour and 
women's work. This essentially leads to further questions for research regarding: how diverse economies are gendered? How gender is reinforced and reproduced through the materialities and practices of such diverse spaces? And, how notions of CE/SE are likewise gendered in these spheres?

\section{Conclusion}

This article has focused upon the materialities of two distinct diverse provisioning economies to illuminate how ordinary practices of circularity and sharing are at work in these novel and new spaces. In doing so, it has illuminated that popular, contemporary notions of circular and shared economy are already at play in informal and often hidden spaces of everyday work and sociality. The article has made three key contributions. Firstly, it has demonstrated how a focus on the materialities of diverse economies is a means to understand and make sense of them. Studying the 'blindingly obvious' (Miller, 2010: 51) stuff of provisioning illuminates how these diverse economies are 'made material': their practices, ambiguities and intimacies. This is in part through a follow-thething approach, but it also involves appreciating the agency of such materials and what they afford.

Secondly, and relatedly, this material focus highlights the ordinary practices of circulating and sharing taking place in new, novel and 'non-emergency' provisioning spaces and structures. Clothes swaps, food groups, time banks and 'pay as you feel' cafes (to name but a few) have replaced the jumble sales and 'bring and buys' of 30 years ago. Often organised through digital means and creating 'online communities', such diverse economies seemingly retain few features of age old modes of provision. Yet, whilst their structures may be different, as I have argued their practices are not. Such diverse economies involve reciprocity, exchange, barter, swapping and mutuality, all of which the previous works of Pahl (1984) and Clarke (2001), amongst others, confirm are not new, but are instead part of the ordinary work of everyday life, embedded in everyday social networks. Undoubtedly there are limitations to this article's arguments, not least that its two case studies only scratch the surface of those available. Yet these case studies raise broader questions about the scope of CE and SE. Utilising my own previous work (Author) along with that of others (Hobson, 2016), this paper has brought to the fore the need to open up thinking about the spaces in which $\mathrm{CE} / \mathrm{SE}$ operates, so that the realms of the domestic, the informal and the diverse are not overlooked. Likewise, the extent to which CE/SE are interwoven is a further area of development. Furthermore, a nuanced approach to exploring CE/SE needs to consider how such concepts are not just displayed by various practices, or in particular spaces, but how they are socially and materially embedded in the choreographies of everyday life. 
This relates to the third key argument: that focusing on the materialities of provisioning reveals how they can be both beneficial and troublesome. The case studies have illustrated how the materials of provisioning are the means through which organisations tackle issues such as social exclusion, financial hardship and sustainable resource use. Their sharing and circulating ensures that users of both groups have access to food and clothing, and that waste is reduced. Moreover, I have demonstrated how such materials can become the conduits for the circulation of much more emotions, advice, support, sociality; intangible aspects which are so often overlooked by standard definitions of CE/SE. In contrast, the article has highlighted how such materials can also be troublesome, unsettling the practices of circulating and sharing, and inadvertently reproducing inequalities such diverse economies wish to tackle. At a micro level this can be through their accessibility and suitability of provisioning materials. Yet, at a more macro level it can be through their reproduction of neoliberal, pro-capitalist frameworks of 'Big Society' and waste disposal, as well as long standing issues of gender inequality and the division of the labour. This article can only offer a partial and provisional contribution to wider debates on diverse economies, alternative provisioning and the circular and shared economy. Yet, it has demonstrated the need for, and will hopefully initiate, further academic research on diverse economies and their intersections with the heterogeneous landscape of economic formations.

\section{Bibliography}

Abu-Ghunmi, D., Abu-Ghunmi, L., Kayal, B., Bino, A., 2016. Circular economy and the opportunity cost of not "closing the loop" of water industry: The case of Jordan. Journal of Cleaner Production 131, 228-236.

Amin, A. 2009. Extraordinarily ordinary: Working in the social economy. Social Enterprise Journal 5(1), 30-49.

Belk, R., 2014a. You are what you can access: Sharing and collaborative consumption online. Journal of Business Research, 67(8), 1595-1600

Belk, R., 2014b. Sharing Versus Pseudo-Sharing in Web 2.0. Anthropologist, 18(1), 7-23.

Botsman, R., Rogers, R., 2011. What's mine is yours: The rise of collaborative consumption. London: HarperCollins Business.

Caplan, P., 2016. Big society or broken society? Food banks in the UK. Anthropology Today 32(1), 59. 
Clarke, A., 2001. The Practice of the Normative: the Making of Mothers, Children and Homes in north London. http://discovery.ucl.ac.uk/1317584/1/252292.pdf

Cook, I., 2004. Follow the thing: papaya. Antipode 36 (4), 642-664.

Coren, C., Clamp, C., 2014. The experience of Wisconsin's wine distribution Co-operatives. Journal of Co-operative Organization and Management 2(1), 6-13.

Daya, S., Authar, R., 2012. Self, others and objects in an "alternative economy": Personal narratives from the Heiveld Rooibos cooperative. Geoforum 43(5), 885-893.

Ellen MacArthur Foundation, 2012. Towards the Circular Economy: Economic and Business

Rationale for an Accelerated Transition.

https://www.ellenmacarthurfoundation.org/assets/downloads/publications/Ellen-MacArthur-

Foundation-Towards-the-Circular-Economy-vol.1.pdf

European Commission, 2015. Towards a circular economy. Retrieved from:

https://ec.europa.eu/priorities/iobs-growth-and-investment/towards-circular-economy en

Evans, D., 2012. Binning, gifting and recovering: The conduits of disposal in household food consumption. Environment and Planning D: Society and Space 30, 1123-1137.

Fickey, A., 2011. "The focus has to be on helping people make a living": Exploring diverse economies and alternative economic spaces. Geography Compass 5(5), 237-248.

Gibson-Graham, J. K., 2008. Diverse economies: Performative practices for "other worlds." Progress in Human Geography 32(5), 613-632.

Gibson, C., Waitt, G., Walmsley, J., Connell, J., 2009. Cultural festivals and economic development in Nonmetropolitan Australia. Journal of Planning Education and Research 29(3), 280-293.

Gregson, N., 2007. Living with things: Ridding, accommodation, dwelling. London, United Kingdom:

Sean Kingston Publishing.

Gronow, J., 2001. Ordinary consumption. New York: Routledge.

Hall, S. M., Ince, A., 2017. Introduction: Sharing Economies in Times of Crisis. In Ince, A., Hall, S.M.,

(Eds.) Sharing economies in times of crisis: Practices, politics and possibilities (pp. 1-14). United Kingdom: Routledge.

Hetherington, K., 2004. Secondhandedness: Consumption, disposal and absent presence, Environment and Planning D 22(1), 157-173.

Heinrichs, H., 2013. Sharing Economy: A Potential New Pathway to Sustainability. GAIA 22(4), 228231.

Hobson, K., 2016. Closing the loop or squaring the circle? Locating generative spaces for the circular economy. Progress in Human Geography 40(1), 88-104. 
Humphries, C., Smith, A., (2014). Talking objects: towards a post-social research framework for exploring object narratives, Organization 21(4), 477-494.

Ince, A., Hall, S. M. (Eds.), 2017. Sharing economies in times of crisis: Practices, politics and possibilities. United Kingdom: Routledge.

Indices of multiple deprivation. 2015, September.

https://www.gov.uk/government/statistics/english-indices-of-deprivation-2015

James, E. C., 2010. Democratic insecurities. ; violence, trauma, and intervention in Haiti. Berkeley: University of California Press.

Jonas, A., 2010. "Alternative" This, "Alternative" That... : Interrogating Alterity and Diversity. In Lee, R., Jonas, A.E.G., Fuller, D. (Eds.) Interrogating alterity: Alternative economic and political spaces (pp. 3-27). United Kingdom: Ashgate Publishing.

Jones, P. A., 2008. From tackling poverty to achieving financial inclusion-The changing role of British credit unions in low income communities. The Journal of Socio-Economics 37(6), 21412154.

Joy, A., Sherry, J. F., Venkatesh, A., Wang, J., Chan, R., 2012. Fast fashion, sustainability, and the ethical appeal of luxury brands. Fashion Theory: The Journal of Dress, Body \& Culture 16(3), 273-296.

Lacy, P., Rutqvist, J., 2015. Waste to wealth: The circular economy advantage. United Kingdom: Palgrave Macmillan.

Leaver, A., Williams, K., 2014. After the 30-year experiment: The future of the "foundational economy." Juncture 21(3), 215-221.

Lee, R., 2010. Spiders, Bees or Architects? Imagination and the Radical Immanence of Alternatives/Diversity for Political-Economic Geographies. In Lee, R., Jonas, A.E.G., Fuller, D. (Eds.) Interrogating alterity: Alternative economic and political spaces (pp. 273-287). Farnham, United Kingdom: Ashgate Publishing.

Lee, R., Leyshon, A., Smith, A., 2008. Rethinking economies/economic geographies. Geoforum 39(3), 1111-1115.

Lieder, M., Rashid, A., 2016. Towards circular economy implementation: A comprehensive review in context of manufacturing industry. Journal of Cleaner Production 115, 36-51.

Martin, C. J., 2016. The sharing economy: A pathway to sustainability or a nightmarish form of neoliberal capitalism? Ecological Economics 121, 149-159.

McLain, R. J., Hurley, P. T., Emery, M. R., Poe, M. R., 2013. Gathering "wild" food in the city: Rethinking the role of foraging in urban ecosystem planning and management. Local Environment 19(2), 220-240. 
McRobbie, A., 1989. Zoot suits and second-hand dresses: An anthology of fashion and music.

Boston: HarperCollins Publishers.

Miller, D., 1987. Material culture and mass consumption. Oxford, OX, UK: Blackwell Publishers.

Miller, D., 2010, Stuff, Cambridge: Wiley, John \& Sons.

Morgan, K., 2014. Nourishing the city: The rise of the urban food question in the global north. Urban Studies 52(8), 1379-1394.

Morgan, K., 2015. The moral economy of food. Geoforum 65, 294-296.

Morris, L., 2016. The moral economy of austerity: Analysing UK welfare reform. The British Journal of Sociology 67(1), 97-117.

Mort, F., 2000. Commercial cultures: Economies, practices, spaces. New York: Berg Publishers.

Niinimäki, K., Hassi, L., 2011. Emerging design strategies in sustainable production and consumption of textiles and clothing. Journal of Cleaner Production 19 (16), 1876-1883.

Norris, L., 2005. Cloth That Lies: The Secrets of Recycling in Indi'. In Kuchler, S., Miller, D. (Eds.) Clothing as Material Culture. Oxford: Berg.

Office for National Statistics, 2016, May. Persistent poverty in the UK and EU: 2014.

https://www.ons.gov.uk/peoplepopulationandcommunity/personalandhouseholdfinances/i ncomeandwealth/articles/persistentpovertyintheukandeu/2014

Office for National Statistics 2016, November. The value of your unpaid labour.

http://visual.ons.gov.uk/the-value-of-your-unpaid-work/

Paddock, J., 2015. Positioning food cultures: "Alternative" food as distinctive consumer practice. Sociology.

Pahl, R. E. E., 1984.Divisions of labour. Oxford: Blackwell Publishers.

Piscicelli, L., Cooper, T., Fisher, T., 2015. The role of values in collaborative consumption: Insights from a product-service system for lending and borrowing in the UK. Journal of Cleaner Production 97, 21-29.

Polanyi, K., 1957. The great transformation the political and economic origins of our time. Boston, MA: Beacon Press.

Potter, L., Westall, C., 2013. Neoliberal Britain's austerity Foodscape: Home economics, Veg patch capitalism and culinary Temporality. New Formations 80(80), 155-178.

Purvis, K., 2014, September 25. How to set up a clothes swap in your area. The Guardian. https://www.theguardian.com/lifeandstyle/2014/sep/15/how-to-set-up-clothes-swap-in-yourarea

Richardson, L., 2015. Performing the sharing economy. Geoforum 67, 121-129.

Sayer, A., 2000. Moral economy and political economy. Studies in Political Economy 61(1), 79-103. 
Sayer, A., 2003. (de)commodification, consumer culture, and moral economy. Environment and Planning D: Society and Space 21(3), 341-357.

Sayer, A., 2015. Time for moral economy? Geoforum 65, 291-293.

Schor, J. B., Fitzmaurice, C., Carfagna, L. B., Attwood-Charles, W., Poteat, E. D., 2016. Paradoxes of openness and distinction in the sharing economy. Poetics $54,66-81$.

Schor, J. B., Walker, E. T., Lee, C. W., Parigi, P., Cook, K., 2015. On the sharing economy. Contexts 14(1), 12-19.

Shelter, 2016. What is the housing crisis.

http://england.shelter.org.uk/campaigns_/why_we_campaign/the_housing_crisis/what_is_the_ housing_crisis

Shove, E., 2003. Comfort, cleanliness and convenience: The social organization of Normality. Oxford, England: Berg Publishers.

Smith, A., Stenning, A., 2006. Beyond household economies: Articulations and spaces of economic practice in postsocialism. Progress in Human Geography 30(2), 190-213.

Sonnino, R., Griggs-Trevarthen, C., (2013). A resilient social economy? Insights from the community food sector in the UK. Entrepreneurship \& Regional Development 25(3-4), 272-292.

Tchoukaleyska, R., 2013. Regulating the farmers' market: Paysan expertise, quality production and local food. Geoforum 45, 211-218.

Thompson, E. P., 1991. Customs in common. Pontypool, Wales: The Merlin Press.

Tukker, A., 2015. Product services for a resource-efficient and circular economy - a review. Journal of Cleaner Production 97, 76-91.

van der Zee, B., 2014, September 25. Swap till you drop: Why a clothing exchange beats London fashion week. The Guardian. https://www.theguardian.com/lifeandstyle/2014/sep/15/swap-tillyou-drop-clothing-exchange-beats-london-fashion-week

Vecchio, R., 2011. Italian and United States farmers' markets: Similarities, differences and potential developments. Journal of Food Products Marketing 17(2-3), 386-406.

White, R. J., 2009. Explaining why the non-commodified sphere of mutual aid is so pervasive in the advanced economies. International Journal of Sociology and Social Policy 29(9/10), 457-472.

Wills, J., 2012. The geography of community and political organisation in London today. Political Geography 31(2), 114-126.

Wilson, M., Jackson, P., 2016. Fairtrade bananas in the Caribbean: Towards a moral economy of recognition. Geoforum 70, 11-21.

Woodward, I., 2007 “Material Culture, Narratives and Social Performance', in Woodward, I. (Ed.) Understanding Material Culture, (pp. 151-68). London: Sage. 
Woodward, S., 2015 'Object interviews, material imaginings and 'unsettling' methods:

interdisciplinary approaches to understanding materials and material culture'. Qualitative Research 16 (4), 359-374.

WRAP, 2016, May. Valuing Our Clothes. http://www.wrap.org.uk/content/valuing-our-clothes

WRAP, 2017. WRAP and the circular economy. http://www.wrap.org.uk/about-us/about/wrap-andcircular-economy.

Zelizer, V. A., 2013. Economic lives: How culture shapes the economy. Princeton, NJ, United States: Princeton University Press. 